\title{
Applying art and science in lipoabdominoplasty: technical and safety considerations
}

\author{
Konstantinos Seretis \\ Department of Plastic Surgery, loannina University Hospital, loannina 45500, Greece.
}

Correspondence to: Assist. Prof. Konstantinos Seretis, Department of Plastic Surgery, Medical School, University of loannina, Leof. St. Niarchou, loannina 45500, Greece. E-mail: drseretis@uoi.gr

How to cite this article: Seretis K. Applying art and science in lipoabdominoplasty: technical and safety considerations. Plast Aesthet Res 2021;8:51. https://dx.doi.org/10.20517/2347-9264.2021.71

Received: 21 Jun 2021 First Decision: 20 Jul 2021 Revised: 20 Jul 2021 Accepted: 9 Aug 2021 Published: 13 Sep 2021

Academic Editors: Karol A. Gutowski, Dennis Hurwitz Copy Editor: Xi-Jun Chen Production Editor: Xi-Jun Chen

\begin{abstract}
Aim: Abdominoplasty has gained in popularity due to the advances in concepts and techniques. The objective of this article is to present a modern abdominoplasty approach, which combines technical elements and evidencebased medicine, in order to achieve consistent aesthetic outcomes and high patient satisfaction rates while limiting the risk of complications.
\end{abstract}

Methods: A detailed description of the lipoabdominoplasty technique is presented. Liposuction of the trunk is combined with dermolipectomy of the anterior abdomen and rectus abdominis muscle plication in a standardized fashion.

Results: In this study, lipoabdominoplasty was performed on 93 patients. The mean hospital stay and time of drain removal were 1.2 and 8.1 days, respectively. The technique was associated with enhanced aesthetic outcomes, in terms of body contouring and definition, high satisfaction rate, and low rate of complications. Minor revisions were performed in $12 \%$ of cases, under local anesthesia.

Conclusion: Safe and consistent outcomes can be achieved by a meticulous lipoabdominoplasty technique, based on the accumulated evidence, thorough anatomical and surgical knowledge, and the artistic acumen of a plastic surgeon. 
Keywords: Abdominoplasty, liposuction, lipoabdominoplasty, high definition

\section{INTRODUCTION}

Abdominoplasty presents one of the most popular aesthetic operations performed worldwide ${ }^{[1]}$. This fact is attributed to the constantly improved outcomes achieved due to the evolution of the concepts and techniques applied ${ }^{[2-9]}$. Illouz ${ }^{[3]}$ in the 1990s supported the use of liposuction in combination with abdominoplasty. Matarasso ${ }^{[4]}$ proposed safe areas of liposuction during concomitant abdominoplasty, while Lockwood ${ }^{[5]}$ presented the high lateral tension abdominoplasty, using the Scarpa fascia to suspend the abdominal flap and thus decrease the tension of the skin closure. Shestak ${ }^{[6]}$ and Avelar ${ }^{[7]}$ presented similar techniques of abdominoplasty with liposuction, avoiding the flap undermining. In 2001, Saldanha et al..$^{[8]}$ first used the term lipoabdominoplasty for his combined technique, which incorporated selective flap undermining. His results were corroborated by a following study in 2009, showing reduced incidence of complications and surgical revisions with lipoabdominoplasty compared to traditional abdominoplasty ${ }^{[9]}$. In 2007, Hoyos et al. ${ }^{[1,11]}$ presented the vibration amplification of sound energy at resonance (VASER) liposculpture technique for high definition of the treated areas, extending its use in abdominoplasty to expedite fat extraction, preserve vascularization, and enhance the aesthetic outcomes. Wall ${ }^{[12]}$ combined abdominoplasty with circumferential liposuction of the trunk, using a three-step standardized liposuction method, with the aim to optimize the flap blood supply and eliminate contour irregularities. Further modifications of the lipoabdominoplasty have been presented over the years.

The objective of this article is to present a modern abdominoplasty approach, which combines technical elements from the aforementioned techniques based on the available evidence, aiming to improve the longterm outcomes and patient satisfaction while limiting the risk of complications following abdominoplasty.

\section{METHODS}

\section{Patient selection and optimization}

A thorough preoperative clinical examination and discussion is important. The indications for lipoabdominoplasty are not different from those of traditional abdominoplasty. Healthy patients with a stable weight for at least two months and a body mass index of less than 30 are the best candidates. Smoking should be stopped at least four weeks before surgery. Optimization of the body weight, diet, and exercise are also encouraged, delaying or cancelling surgery if necessary. The venous thromboembolism (VTE) risk is always assessed by means of the Caprini score ${ }^{[13]}$.

\section{Markings}

With the patient standing, the abdomen is marked. First, a line connects the xiphoid with the anterior labial commissure. The lower abdominoplasty markings are delineated $6-7 \mathrm{~cm}$ superior to anterior labial commissure, exerting strong traction on the skin. From the central point, a $6 \mathrm{~cm}$ horizontal line is extended laterally and then $8 \mathrm{~cm}$ obliquely with 45 degrees of inclination on each side towards the iliac crest. The upper markings, based on skin pinch test with the patient bending forward, are outlined above the umbilicus centrally and arching laterally and checked and verified intraoperatively, before pannus excision. The lower incision markings are never adjusted intraoperatively.

The costal margins, rectus abdominis muscle origin and insertion, xiphoid, and inframammary folds are also marked as anatomical landmarks. The linea semilunaris and the areas in the flanks and dorsum to undergo liposuction are also outlined. "Shadow" areas for postlipectomy liposuction are marked below the costal margins and lateral to the lower insertion of the rectus abdominis muscle. The diastasis can also be 
marked in advance for better orientation.

\section{General surgical considerations}

Knee-high sequential compression devices are applied in the operation theatre (OR) and used until the patient is completely ambulatory. Measures to avoid hypothermia include the patient transfer to the OR covered with blanket, adjustment of room temperature, and use of only warmed intravenous fluids, wetting solution and betadine. Perioperative antibiotic prophylaxis is given before the induction of anesthesia and a bladder catheter is inserted while the patient is under general anesthesia and retained until patient mobilization.

\section{Surgical technique}

All areas to be lipoaspirated are infiltrated with a solution containing $1 \mathrm{~L}$ lactated Ringer, $200 \mathrm{mg}$ of lidocaine, $1 \mathrm{mg}$ of epinephrine, and, recently, $1 \mathrm{~g}$ of tranexamic acid as well, adhering to the guidelines of the American Society of Plastic Surgeons ${ }^{[14]}$. Infiltration to the point of tissue saturation is performed. The infiltration/aspiration volume ratio is 1-1.5:1, and a mean total infiltrate of $2-3 \mathrm{~L}$ is used.

The patient is placed first in a prone position for the liposuction of the back, flanks, and trochanteric areas with 4 and $5 \mathrm{~mm}$ standard angled cannulas, using the three-step SAFELipo technique consisting of separation, aspiration, and fat equalization ${ }^{[12]}$. This process is repeated in the supine hyperextended position for the liposuction of the flanks, the suprapubic area, and the thoracoabdominal area superolateral to the flap. Enough fat of equally distributed thickness is maintained to avoid vascular impairment and contour deformities.

Abdominoplasty is started through the lower marking, elevating the flap in the sub-Scarpa plane, leaving a thin layer of fat and the loose areolar tissue above the deep fascia intact. On reaching the umbilicus level, the flap is split, and the umbilicus released from the flap. Dissection of the tunnel proceeds from the umbilicus to the xiphoid, extending conservatively laterally, in order to preserve as many of the superior perforators of the abdominal wall as possible, without compromising flap advancement. Diastasis repair is performed to the extent indicated, using a single \# 1 looped polydioxanone (PDS) suture running from the xiphoid down to the pubis.

Then, the excess abdominal skin is assessed by placing the patient in a semi-Fowler position $\left(45^{\circ}\right)$. The skin flaps are advanced medially and inferiorly, aiming to secure the flap with minimal tension. The excess skin is excised incorporating also the sub-Scarpa's fat of the undermined flap. The midline is enhanced by a progressive continuous o polyglactin 910 (Vicryl) suture from the xiphoid down to the umbilicus. Several interrupted progressive tension 2-0 PDS or Vicryl sutures are also placed over each rectus fascia. Two drains are placed and sutured in the suprapubic area and left until daily drainage output is less than $30 \mathrm{~mL}$. Closure is performed in layers, securing first the flap centrally, by placing a figure-8 2-0 PDS suture to the Scarpa's fascia, also incorporating the rectus fascia. Closure then proceeds from lateral to medial, using 3-0 Monocryl sutures for the Scarpa's fascia, taking the tension off the midline as described by Lockwood ${ }^{[5]}$. Monocryl 3-0 suture is also used for the subcuticular suture. The umbilicus is exteriorized through a $2 \mathrm{~cm} \times 1 \mathrm{~cm}$ opening of the skin 1.5-2 cm above the projected location of the umbilicus, in order to avoid excessive tension to the suprapubic area. Four 3-0 Monocryl cardinal stitches fix the umbilicus to the abdominal fascia and further dermal stitches complete the umbilicoplasty. Before completion of the closure, muscular definition can be enhanced performing additional liposuction, targeting the linea semilunaris and creating negative spaces (subcostal, suboblique, and pubic triangle) as described by Hoyos and Millard ${ }^{[10]}$. 
The wound is covered with Steri-strips, gauzes, and Micropore surgical tape (3M, St. Paul, MN, USA). A foam is placed over the abdomen and especially over the areas of superficial liposuction to help further flatten and define these areas. A binder is worn for 3 weeks and a compression garment for 8-12 weeks after surgery.

The patient is usually discharged the first postoperative day with instructions and scheduled outpatient visits for assessment and drain and suture removal.

\section{RESULTS}

This surgical technique, combining liposuction with abdominoplasty, was performed on 93 female patients with an average age of 38 years (20-67 years). No other concomitant procedures apart from liposuction were performed during the surgery. The mean hospital stay and time of drain removal were 1.2 and 8.1 days, respectively.

This lipoabdominoplasty variation was associated with enhanced aesthetic outcomes, in terms of body contouring and definition, high satisfaction rate, and low rate of complications and/or surgical revisions. Common complications of traditional abdominoplasty, such as wound dehiscence and necrosis, never occurred, while minor seroma with no further sequala occurred once. No cases of hematoma or deep venous thrombosis were recorded. Minor surgical revisions, due to dog ears or scar hypertrophy, were performed in $12 \%$ of cases, under local anesthesia.

Patient examples are depicted in Figures 1-3.

\section{DISCUSSION}

A plethora of abdominoplasty techniques have been used to address the anterior abdomen. Lipoabdominoplasty has transformed body contouring surgery, aiming not only to correct the musculofascial wall laxity and remove the excess skin and adipose tissue of the lower abdomen, but also to define the entire abdomen and flanks, enhancing the long-term aesthetic outcome. This technique is not simply the combination of liposuction with traditional abdominoplasty. It is a much wider concept, characterized by adequate preservation of the blood supply of the abdomen, focus on the pertinent anatomy, and use of relevant surgical algorithms and techniques to completely address each anatomical area and layer, namely excess skin and adipose tissue, rectus diastasis, inadequate abdominal, flanks, and waist definition, with safety and low complication risks.

The power of the lipoabdominoplasty technique has affected the aesthetic ideals towards a more defined abdominal contour, while the active and athletic modern lifestyle is literally mirrored to the applied techniques. Matarasso ${ }^{[4]}$ considered the flanks and the back as safe areas of liposuction based on Huger ${ }^{[15]}$ 's vascular anatomy of the anterior abdominal wall. Saldanha et al. ${ }^{[8]}$ showed improved aesthetic results incorporating liposuction of these areas to abdominoplasty. Hoyos and Millard ${ }^{[10]}$ analyzed the torso anatomy, visualized the changes induced by liposuction, in terms of natural superficial light and shadows, and applied his VASER abdominoplasty technique in a standardized fashion. In that respect, the waist is better defined and the waist-to-hip ratio ideal of 0.7 is approached ${ }^{[16]}$. The "high definition" concept, although not universally accepted, can be applied with this technique in the anterior abdomen of both genders to achieve body sculpting and shaping. 

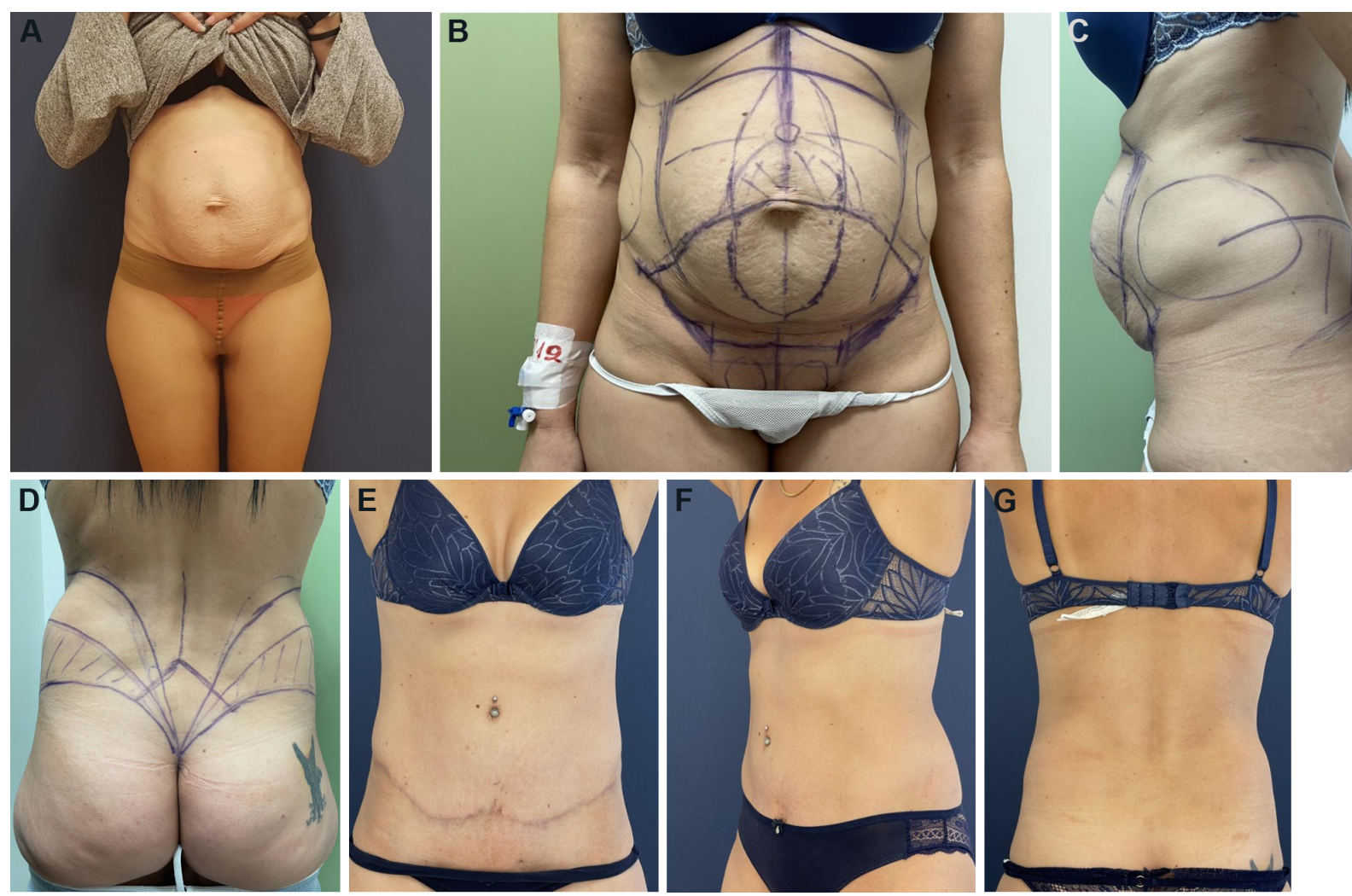

Figure 1. A 36-year-old woman with BMI of $22 \mathrm{~kg} / \mathrm{m}^{2}$ and four caesarean sections, who underwent lipoabdominoplasty, before (A-D) and nine months after $(\mathrm{E}-\mathrm{G})$ surgery. Notice the correction of the large diastasis and the definition of the abdomen, waistline, and back.
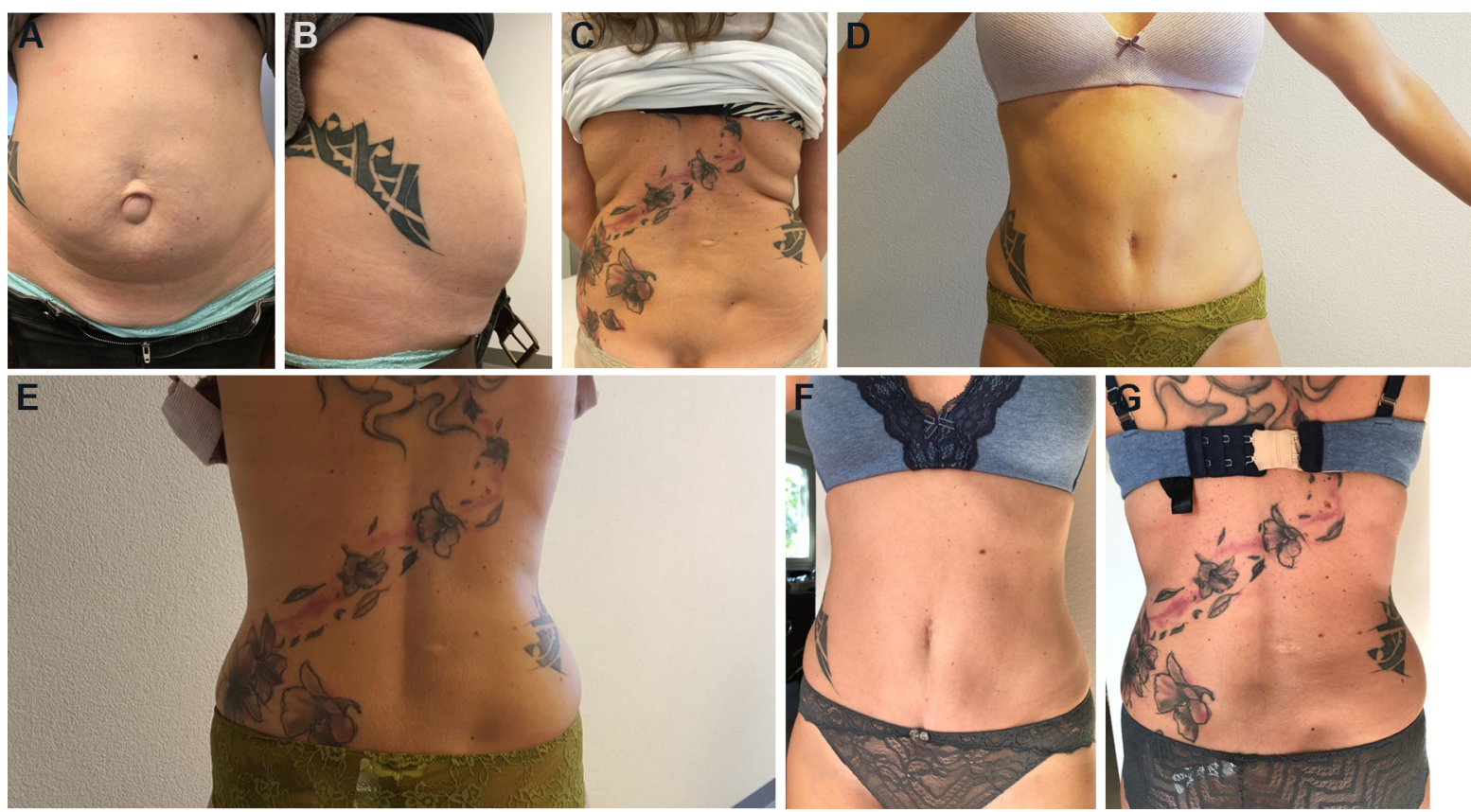

Figure 2. A 41-year-old woman with BMI of $21 \mathrm{~kg} / \mathrm{m}^{2}$ who underwent lipoabdominoplasty, before (A-C) and one year after (D-G) surgery. Notice the diastasis and hernia repair and the definition of the abdomen, waistline, and back. 

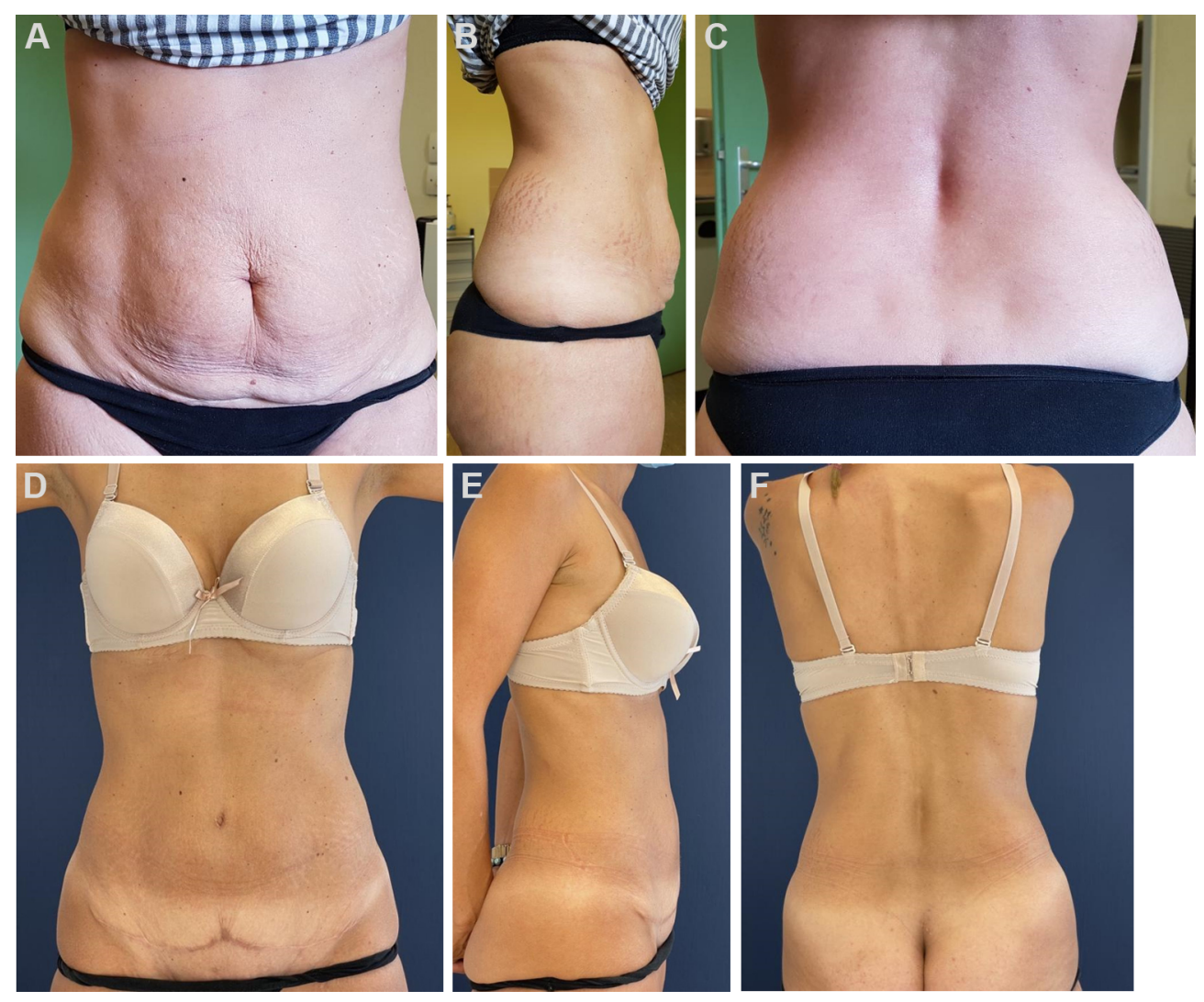

Figure 3. A 35-year-old woman with BMI of $24 \mathrm{~kg} / \mathrm{m}^{2}$ who underwent lipoabdominoplasty, before (A-C) and 2.5 years after (D-F) surgery. Notice the definition of the abdomen, waistline and back.

Liposuction of the thoracoabdominal area, superior and lateral to the flap, debulks an area which is not treated by abdominoplasty alone. In fact, cannula undermining has substituted the traditional flap undermining, preserving the vascular supply of the abdominal flap, while permitting its debulking, without increasing the risk of necrosis or complications. Sozer et al ${ }^{[17]}$ showed in a series of 1000 patients that applying widespread circumferential liposuction with standard abdominal flap undermining up to the costal margins is safe and associated with improved aesthetic results. Similar results, concerning safety and patient satisfaction, have been also reported following concurrently performing liposuction and abdominoplasty ${ }^{[18-20]}$. Roostaeian et al. ${ }^{[2]]}$ conducted a prospective study in 18 patients, employing SPY fluorescent imaging (LifeCell Corp, Bridgewater, NJ), which showed that the rates of intraoperative abdominal flap perfusion or postoperative complications are not significantly different between lipoabdominoplasty and traditional abdominoplasty.

The technique presented herein, SAFElipo, accomplished the safety issue, in terms of the flap vascular supply ${ }^{[12]}$. Suction is not used during the fat separation and equalization phases, which diminishes the risk of avulsion injury to the vessels. Fat equalization also minimizes the risk of contour irregularities by creating a layer of separated fat, which acts as a buffer zone during the healing phase. Consistent results can be achieved following the SAFELipo steps meticulously. Of note, our approach involves standard cannulas instead of the power-assisted cannulas by Wall or VASER system by Hoyos, exemplifying the importance of the technique and the surgical artistry instead of the device use. 
Following the completion of liposuction, lipectomy is performed based on the principles set by Saldanha et al. ${ }^{[8,9]}$. The width of dissection above the umbilicus is limited, preserving perforators from the deep superior epigastric artery, as confirmed by the Doppler flowmetry color study of the abdominal wall of Graf et al. ${ }^{[22]}$. Smith and Smith ${ }^{[20]}$ reviewed 300 consecutive cases and showed that abdominoplasty with abdominal liposuction is safe when a perforator vessel is spared. These perforators are expected in a $2 \mathrm{~cm}$ radius located $4 \mathrm{~cm}$ from the midline and $6 \mathrm{~cm}$ from the subcostal margin.

Contrary to the Saldanha's technique with sub-Scarpa's fat preservation, we prefer excision of most of this deep fat, reducing both the thickness of the flap and its metabolic needs, which also improves the blood supply. Swanson ${ }^{[23]}$ in 2015 used intraoperative laser perfusion imaging to show that the perfusion of the abdominoplasty flap following limited dissection abdominoplasty with sub-Scarpa's fat preservation is not significantly different from that of full abdominoplasty with sub-Scarpa's fat removal. Tourani et al. ${ }^{[2]}$ conducted an anatomic study, which showed that the lymphatic drainage of the lower abdomen lies superficial to Scarpa's fascia and the transition to the infra-Scarpa fascial plane occurs within $2-3 \mathrm{~cm}$ of the inguinal ligament. Interestingly, a systematic review of four studies concluded that Scarpa's fascia preservation is associated with significantly decreased seroma rate, drain output, time to drain removal, and hospital stay ${ }^{[25]}$. In a meta-analysis, we showed that certain preventive measures, namely Scarpa's fascia preservation, tissue adhesives, and use of progressive tension sutures (PTS), significantly reduce the seroma and infection rates, time to drain removal, and the length of hospital stay ${ }^{[26]}$. Based on this evidence, we prefer to leave a thin layer of fat and the loose areolar layer above the deep fascia intact.

In addition, PTS, as first described by Pollock and Pollock ${ }^{[27]}$, are used prophylactically to minimize the dead space and shearing forces between the flap and the underlying fascia. In their study of 597 consecutive abdominoplasty cases without drains, PTS use facilitated abdominal flap advancement, while the seroma rate was only $0.8 \%{ }^{[28]}$. Similarly, Antonetti and Antonetti ${ }^{[29]}$ reviewed 516 consecutive cases and showed that the adoption of PTS was associated with a dramatic decrease in the seroma rate (from $24 \%$ to $1.7 \%$ ). Gould et al. ${ }^{[30]}$ also reported significantly lower seroma rates with PTS usage in 619 patients who underwent either drainless lipoabdominoplasty with PTS or drain-based lipoabdominoplasty. A clinical trial showed that the seroma rate was reduced to $3.5 \%$ by placing PTS and 11 sutures were as efficient at preventing seroma as the usage of 22 PTS, with the additional benefit of reduced surgical time $(13 \mathrm{~min} v \mathrm{~s} .30 \mathrm{~min})^{[31]}$. Based on the above, we use a continuous PTS to enhance the midline from the xiphoid down to the umbilicus instead of 3-4 interrupted PTS and 7-8 interrupted PTS to stabilize the remaining abdominal flap. Interestingly, neither our results nor other studies associate PTS practice with increased rates of complications.

Apart from the technical aspects of abdominoplasty, consideration should also be given to VTE prophylaxis due to the inherited risks of operations. Increased intraabdominal pressure following muscle plication, binder use, and postoperative patient positioning and immobilization are known risk factors. In a recent review, obesity, circumferential procedures, and hormone replacement therapy were independent risk factors for VTE in abdominoplasty patient ${ }^{[32]}$. These findings are corroborated by a previous systematic review of VTE risk in abdominal contouring procedures, which demonstrated that circumferential abdominoplasty and abdominoplasty performed in combination with intra-abdominal procedures had increased risk for VTE (3.4\% and $2.17 \%$, respectively $)^{[33]}$. Abdominoplasty alone had the lowest rate $(0.35 \%)$, which was doubled in abdominoplasty with concomitant plastic surgery procedures (0.79\%). Based on this evidence, we avoid the routine combination of lipoabdominoplasty with other procedures. Furthermore, preoperative risk stratification based on the Caprini score is applied. A score greater than 7 or 8 necessitates chemoprophylaxis ${ }^{[34]}$. Despite the concerns that chemoprophylaxis increases bleeding complications, recent 
studies refute this notion and support its use in the prevention of VTE risk ${ }^{[35,36]}$. Surgeons should choose VTE prophylaxis taking into consideration the patient and operative risk factors. Our VTE prophylaxis protocol also comprises preoperative patient optimization, compression stockings, and use of a sequential compression device intraoperatively and early ambulation postoperatively.

In conclusion, this paper presents a safe and efficacious variation of lipoabdominoplasty, using standard liposuction cannulas. Despite the marketing and innovations of liposuction devices, such as radiofrequency-, laser-, and vibration-assisted liposuction devices, consistent results can be achieved by standard liposuction devices, using a meticulous technique based on the accumulated evidence, thorough anatomical and surgical knowledge, and applied surgical skills.

\section{DECLARATIONS}

\section{Authors' contributions}

The author contributed solely to the article.

\section{Availability of data and materials}

Not applicable.

\section{Financial support and sponsorship}

None.

\section{Conflicts of interest}

The author declared that there are no conflicts of interest.

\section{Ethical approval and consent to participate}

The study conformed to the ethical guidelines of the 1975 Declaration of Helsinki.

\section{Consent for publication}

A written informed consent for publication was obtained.

\section{Copyright}

(c) The Author(s) 2021.

\section{REFERENCES}

1. Aesthetic Society's Cosmetic Surgery National Data Bank: Statistics 2019. Aesthet Surg J 2020;40:1-26. DOI

2. Matarasso A. Abdominolipoplasty: a system of classification and treatment for combined abdominoplasty and suction-assisted lipectomy. Aesthetic Plast Surg 1991;15:111-21. DOI PubMed

3. Illouz YG. A new safe and aesthetic approach to suction abdominoplasty. Aesthetic Plast Surg 1992;16:237-45. DOI PubMed

4. Matarasso A. Liposuction as an adjunct to full abdominoplasty. Plast Reconstr Surg 1995;95:829-36. PubMed

5. Lockwood T. High-lateral-tension abdominoplasty with superficial fascial system suspension. Plast Reconstr Surg 1995;96:603-15. DOI PubMed

6. Shestak KC. Marriage abdominoplasty expands the mini-abdominoplasty concept. Plast Reconstr Surg 1999;103:1020-31; discussion 1032-5. DOI PubMed

7. Avelar JM. Abdominoplasty without panniculus undermining and resection: analysis and 3-year follow-up of 97 consecutive cases. Aesthet Surg J 2002;22:16-25. DOI PubMed

8. Saldanha OR, Pinto EB, Matos WN Jr, Lucon RL, Magalhães F, Bello EM. Lipoabdominoplasty without undermining. Aesthet Surg J 2001;21:518-26. DOI PubMed

9. Saldanha OR, Federico R, Daher PF, et al. Lipoabdominoplasty. Plast Reconstr Surg 2009;124:934-42. DOI PubMed

10. Hoyos AE, Millard JA. VASER-assisted high-definition liposculpture. Aesthet Surg J 2007;27:594-604. DOI PubMed

11. Hoyos A, Perez ME, Guarin DE, Montenegro A. A report of 736 high-definition lipoabdominoplasties performed in conjunction with circumferential VASER liposuction. Plast Reconstr Surg 2018;142:662-75. DOI PubMed

12. Wall S Jr. SAFE circumferential liposuction with abdominoplasty. Clin Plast Surg 2010;37:485-501. DOI PubMed

13. Caprini JA. Thrombosis risk assessment as a guide to quality patient care. Dis Mon 2005;51:70-8. DOI PubMed 
14. The American Society of Plastic Surgeons. Practice Advisory on Liposuction: Executive Summary. Available from: https:/www.plasticsurgery.org/documents/medical-professionals/health-policy/key-issues/Executive-Summary-on-Liposuction.pdf. [Last accessed on 18 Aug 2021].

15. Huger WE Jr. The anatomic rationale for abdominal lipectomy. Am Surg 1979;45:612-7. PubMed

16. Bovet J, Raymond M. Preferred women's waist-to-hip ratio variation over the last 2,500 years. PLoS One 2015;10:e0123284. DOI PubMed PMC

17. Sozer SO, Basaran K, Alim H. Abdominoplasty with circumferential liposuction: a review of 1000 consecutive cases. Plast Reconstr Surg 2018;142:891-901. DOI PubMed

18. Swanson E. Prospective clinical study of 551 cases of liposuction and abdominoplasty performed individually and in combination. Plast Reconstr Surg Glob Open 2013;1:e32. DOI PubMed PMC

19. Xia Y, Zhao J, Cao DS. Safety of lipoabdominoplasty versus abdominoplasty: a systematic review and meta-analysis. Aesthetic Plast Surg 2019;43:167-74. DOI PubMed

20. Smith LF, Smith LF Jr. Safely combining abdominoplasty with aggressive abdominal liposuction based on perforator vessels: technique and a review of 300 consecutive cases. Plast Reconstr Surg 2015;135:1357-66. DOI PubMed PMC

21. Roostaeian J, Harris R, Farkas JP, Barton FE, Kenkel JM. Comparison of limited-undermining lipoabdominoplasty and traditional abdominoplasty using laser fluorescence imaging. Aesthet Surg J 2014;34:741-7. DOI PubMed

22. Graf R, de Araujo LR, Rippel R, Neto LG, Pace DT, Cruz GA. Lipoabdominoplasty: liposuction with reduced undermining and traditional abdominal skin flap resection. Aesthetic Plast Surg 2006;30:1-8. DOI PubMed

23. Swanson E. Comparison of limited and full dissection abdominoplasty using laser fluorescence imaging to evaluate perfusion of the abdominal skin. Plast Reconstr Surg 2015;136:31e-43e. DOI PubMed

24. Tourani SS, Taylor GI, Ashton MW. Scarpa fascia preservation in abdominoplasty: does it preserve the lymphatics? Plast Reconstr Surg 2015;136:258-62. DOI PubMed

25. Xiao X, Ye L. Efficacy and safety of scarpa fascia preservation during abdominoplasty: a systematic review and meta-analysis. Aesthetic Plast Surg 2017;41:585-90. DOI PubMed

26. Seretis K, Goulis D, Demiri EC, Lykoudis EG. Prevention of seroma formation following abdominoplasty: a systematic review and meta-analysis. Aesthet Surg J 2017;37:316-23. DOI PubMed

27. Pollock H, Pollock T. Progressive tension sutures: a technique to reduce local complications in abdominoplasty. Plast Reconstr Surg 2000;105:2583-6; discussion 2587-8. DOI PubMed

28. Pollock TA, Pollock H. Progressive tension sutures in abdominoplasty: a review of 597 consecutive cases. Aesthet Surg $J$ 2012;32:729-42. DOI PubMed

29. Antonetti JW, Antonetti AR. Reducing seroma in outpatient abdominoplasty: analysis of 516 consecutive cases. Aesthet Surg $J$ 2010;30:418-25. DOI PubMed

30. Gould DJ, Macias LH, Saeg F, Dauwe P, Hammoudeh Z, Grant Stevens W. Seroma rates are not increased when combining liposuction with progressive tension suture abdominoplasty: a retrospective cohort study of 619 patients. Aesthet Surg J 2018;38:7639. DOI PubMed

31. Bromley M, Marrou W, Charles-de-Sa L. Evaluation of the number of progressive tension sutures needed to prevent seroma in abdominoplasty with drains: a single-blind, prospective, comparative, randomized clinical trial. Aesthetic Plast Surg 2018;42:1600-8. DOI PubMed

32. Mittal P, Heuft T, Richter DF, Wiedner M. Venous thromboembolism (VTE) prophylaxis after abdominoplasty and liposuction: a review of the literature. Aesthetic Plast Surg 2020;44:473-82. DOI PubMed

33. Hatef DA, Trussler AP, Kenkel JM. Procedural risk for venous thromboembolism in abdominal contouring surgery: a systematic review of the literature. Plast Reconstr Surg 2010;125:352-62. DOI PubMed

34. Pannucci CJ, Bailey SH, Dreszer G, et al. Validation of the Caprini risk assessment model in plastic and reconstructive surgery patients. J Am Coll Surg 2011;212:105-12. DOI PubMed PMC

35. Sarhaddi D, Xu K, Wisbeck A, et al. Fondaparinux significantly reduces postoperative venous thromboembolism after body contouring procedures without an increase in bleeding complications. Aesthet Surg J 2019;39:1214-21. DOI PubMed

36. Vasilakis V, Klein GM, Trostler M, et al. Postoperative venous thromboembolism prophylaxis utilizing enoxaparin does not increase bleeding complications after abdominal body contouring surgery. Aesthet Surg J 2020;40:989-95. DOI 